\title{
Sodium Salicylate
}

National Cancer Institute

\section{Source}

National Cancer Institute. Sodium Salicylate. NCI Thesaurus. Code C834.

The sodium salt of salicylic acid. As a nonsteroidal anti-inflammatory drug (NSAID), sodium salicylate irreversibly acetylates cyclooxygenases I and II, thereby inhibiting prostaglandin synthesis and associated inflammation and pain. This agent may also activate mitogen-activated protein kinase (p38MAPK), thereby inducing apoptosis in cancer cells. ( $\mathrm{NCl04)}$ 